\title{
COMPETÊNCIA E CIDADANIA NO MUNDO DO TRABALHO
}

\author{
Inês Amaro da Silva*
}

SINTESE - Nas proximidades do novo milênio deparamo-nos com a construção de um progresso científico e tecnológico muito intenso, o qual coloca novas dimensões às desigualdades sociais, bem como impõe novas demandas à formação. $O$ atual estágio de desenvolvimento das forças produtivas requer, mais do que nunca, 0 investimento no desenvolvimento humano, abrindo novas possibilidades para um avanço na necessária articulação entre as demandas do mundo do trabalho - expressas na categoria competência - com as do mundo social com um todo, que se manifestam na ampliação dos espaços voltados à construção da cidadania. Esse artigo busca fundamentar a necessidade e a possibilidade dessa articulação, procurando captar possiveis elementos que constituem esse processo, junto às ações de formação desencadeadas pelo SEST/RS.
ABSTRACT - As the new millennium approaches, we are faced with the construction of a very intense scientific and technological progress, which brings new dimensions to the social inequalities, and also imposes new demands on education. The current level of development of the productive forces demands, more than ever, an investment in human development, opening new possibilities for an advance in the necessary articulation between the demands of the working world -- expressed in the category competence - and the demands of the social world as a whole, which are manifested in the broadening of spaces directed towards the construction of citizenship. This article tries to justify the need and the possibility of such an articulation, seeking to pick up, from the educational initiatives unleashed by SESI/RS, possible elements which constitute this process.

Este artigo é parte do projeto de pesquisa "Competência e Cidadania: uma articulação possivel?",' que se propõe a investigar como o SESI/RS - Serviço Social da Indústria do Estado do Rio Grande do Sul - enquanto instituição que atua no âmbito da produção e reprodução da força-de-trabalho, tem contribuído para a formação do cidadão trabalhador, através da instauração da competência e da ampliação e fortalecimento da cidadania.

Tem o presente por objetivo compartilhar com o leitor a revisão de literatura até então realizada e o caminho que vem sendo percorrido na busca dessa possí-

* Assistente Social, mestranda em Serviço Social pela PUCRS, bolsista CAPES.

1 Esta investigação desenvolve-se dentro de uma temática maior sendo uma sublinha de pesquisa do eixo Formação-Trabalho e Cidadania, que articula vários subprojetos e é coordenado pela professora Julieta Beatriz Ramos Desaulniers junto ao Mestrado em Serviço Social e IFCH - PUCRS). 0 presente artigo trata de assuntos abordados num dos capítulos da referida dissertação.

\begin{tabular}{|l|l|l|l|l|l|}
\hline VERITAS & Porto Alegre & v. 42 & $\mathrm{n}^{\circ} 2$ & Junho 1997 & p. 247-264
\end{tabular}


vel articulação entre as categorias competência e cidadania, que se constituem hoje demandas significativas do mundo do trabalho e da sociedade como um todo.

Os sistemas produtivos modernos são extremamente competitivos e requerem um trabalhador competente que faça frente às constantes necessidades de inovação, visando a garantir a competitividade. Embora tal perspectiva de formação do trabalhador seja dada a partir de um modelo neoliberal, basicamente como estímulo à capacidade competitiva (valor instrumental), parece-nos indiscutivel que esse processo se desencadeia no seio de contradições, ocorrendo o desenvolvimento do homem como um todo: nos seus aspectos positivos e negativos. Há, assim, possibilidade de crescimento do ser humano-trabalhador, na perspectiva do desenvolvimento global de suas capacidades e da cidadania, sendo esse um espaço importante a explorar, articulando as demandas do mundo do trabalho, expressas na categoria competência, com as do mundo social como um todo, expressas na categoria cidadania.

Essas demandas de uma forma geral relacionam-se ao extraordinário desenvolvimento científico e tecnológico e às profundas mudanças na organização do trabalho quanto à competência, bem como relacionam-se ao processo democrático e à luta pela diminuição das desigualdades sociais, econômicas, políticas e culturais, ainda mais marcantes nesse final de milênio, no que se refere à cidadania.

$\mathrm{O}$ que vamos aqui refletir parte da hipótese de que, enquanto categoria que condensa as exigências do novo perfil de trabalhador que vem sendo requerido, a formação para a competência possibilita a ampliação e o fortalecimento da cidadania.

\section{O mundo do trabalho e as demandas para a formação}

As complexas transformações que vêm ocorrendo a nível mundial são pautadas, entre outros movimentos, pelo extraordinánio desenvolvimento da ciência e da técnica e por profundas revoluções no campo do conhecimento humano, pelas conseqüentes mudanças na organização do trabalho, associadas à globalização da economia e internacionalização do mercado, bem como pelas novas formas de governo que despontam, onde se enfraquece o modelo do Estado-Nação e as organizações sociais, políticas, econômicas e culturais passam a governar economias e sociedades. Tais transformações colocam uma diversidade de questões e desafios ao desenvolvimento econômico-social, que passa a engendrar-se sob outras bases.

Analisando a chamada sociedade global como um fenômeno social e, embora referindo que sua interpretação esteja ainda no início, Ianni bem comenta que as mudanças em curso dão a impressão de término de uma época, mas não dos desafios, pois reaparecem os graves problemas do Terceiro Mundo e as difíceis condições de vida e trabalho da maioria da humanidade. Como coloca o autor, novas tensões e arranjos, cartografias geopolíticas e polarizações ideológicas confundemse e desfazem-se de um momento para outro, mas o capitalismo, no regime liberal 
democrático que vigora, não é capaz de eliminar as desigualdades sociais, econômicas, políticas e culturais, agora lançadas em escala mundial. ${ }^{2}$

Na sociedade global, as desigualdades reaparecem recriadas em outros niveis, sob outras formas; o capital recobre ou recria formas de vida e trabalho, de ser e de pensar; recriam-se condições para novas formas de organizar a sociedade, de pensar o mundo. A formação da sociedade global, dessa maneira, modifica, substancialmente, as condições de vida e trabalho, os modos de ser, sentir, pensar e imaginar, bem como modifica as condições de alienação e as possibilidades de emancipação de indivíduos, grupos, etnias, minorias, classes, sociedades e continentes. $^{3}$

No contexto destas transformações, o neoliberalismo como sistema produtivo e sócio-político que tem o mercado como regulador da economia e da sociedade vem sendo o modelo adotado em grande parte dos paises de economias centrais e também periféricas. Dentro desse modelo, a garantia da competitividade vem se pautando cada vez mais numa sólida formação dos trabalhadores, pois os avanços já conquistados em termos científicos e tecnológicos necessitam de um indivíduo capaz de lidar com as constantes inovações.

Especialmente nos países do Terceiro Mundo, face aos baixos salários e qualificação precária, um grande desafio é fazer a necessária competitividade, investindo num processo de formação dos trabalhadores que garanta a possibilidade de inserção no mercado dentro da diversidade de formas de emprego hoje vislumbradas. Tais formas de emprego e trabalho vêm constituindo-se na dinâmica das transformações no mundo do trabalho, as quais implicam profundas mudanças nas suas bases materiais, organizacionais e gerenciais, a partir de movimentos do capital que têm sido denominados como neofordismo, neotaylorismo, pósfordismo, toyotismo e especialização e acumulação flexível. ${ }^{4}$

Considerando que a introdução das mudanças que se operam a nivel políticoeconômico e a nivel industrial tem se colocado como exigência para sobrevivência e participação no mercado mundial, num contexto de economia globalizada, de internacionalização do mercado e de competitividade, a questão é em que condições tais mudanças estão sendo realizadas e até que ponto poderão contribuir para responder também aos desafios que se colocam em termos de superação dos grandes problemas sociais como a fome, a miséria e as desigualdades e especialmente no que se refere à questão do emprego, que é o âmbito deste estudo.

Sobre esse aspecto, o atual desenvolvimento científico e tecnológico traz também essa contradição, pois ao dispor da ciência e da tecnologia, o capital pode aumentar sua produtividade sem, necessariamente, demandar um maior número de trabalhadores, crescendo o contingente de excluídos e desempregados. Podese dizer, assim, que o modelo neoliberal tem sido tanto a base da modernização a que uns têm acesso, quanto a razão da excludência para uma grande maioria.

IANNI, Otávio. A sociedade Global. Rio de Janeiro: Civilização Brasileira, 1995, p. 11 a 33.

3 Idem, p. 35 a 52.

4 ANTUNES, Ricardo. Adeus ao Trabalho - Ensaio sobre as metamorfoses e a centralidade do mundo do trabalho. São Paulo: Cortez; Campinas, SP: Editora da Universidade Estadual de Campinas, 1995, p. 13 a 38. 
Nesse contexto, a exigência de um novo perfil do trabalhador, dada pelo desenvolvimento de diferentes processos de trabalho, requer novos conhecimentos e saberes necessários à realidade em mudança. A formação desse perfil coloca-se como condição mínima de garantia do emprego e da empregabilidade, sendo preciso instaurar nos indivíduos as disposições ${ }^{6}$ que os capacitem a dar conta das novas formas de viver e trabalhar que vêm sendo engendradas neste final de milênio.

É dentro dessa realidade que Desaulniers aponta, baseada especialmente em autores franceses, que o termo formação vem assumindo destaque nas duas últimas décadas. ${ }^{6}$ Especificamente no tocante aos países de economia periférica, como bem coloca a autora, o desafio é duplo, pois trata-se de ampliar as ações voltadas à qualificação (saber-fazer), dando conta, simultaneamente, dos pressupostos que garantem uma formação que possa instaurar a competência.' Nesta, "a relação cognitiva tende a se definir sobre o modo-de-ser (ser competente) e não mais sobre aquele de ter (ter um saber com o risco de perdê-lo) a competência"."

Discutindo as relações entre formação e emprego a partir da crise estrutural das economias ocidentais e dos processos de reestruturação produtiva, Lope y Artiles observam que a segmentação do mercado de trabalho reestrutura e condiciona a formação como elemento de acesso ao emprego. A segmentação do mercado implica diferentes exigências e introduz outros conteúdos nọ conceito de formação, assumindo maior relevância as capacidades comumente adquiridas fora do sistema educativo. ${ }^{\circ}$

Ao pesquisar o contexto francês e de outras sociedades desenvolvidas, Tanguy analisa a noção de formação enquanto atividade social de transmissão e aquisição de conhecimentos, comportamentos e atitudes que não mais se restringem à escola e está associada a fatos e mudanças estruturais e conjunturais nos níveis

- Referimo-nos aqui à noção de habitus utilizada por Pierre Bourdieu, entendida como um "sistema de disposições duráveis, estruturas estruturadas predispostas a funcionarem como estruturas estruturantes" In BOURDIEU, P. "Esquisse d'une théorie de la pratique" apud ORTIZ, Renato (org.). Pierre Bordieu. Coleção Grandes Cientistas Sociais (39). São Paulo: Ática, 1983, p. 15. O habitus indica a disposição incorporada, mas de um agente em ação. In BOURDIEU, P. O Poder Simbólico. Rio de Janeiro: Ed. Bertrand Brasil, p. 60-64. Como sistema de disposiçōes para a prảtica, o habitus é um fundamento objetivo da regularidade das condutas e obedece a uma lógica da prática, que define a relação cotidiana com o mundo; por outro lado, há uma parcela de indeterminação, de abertura e incerteza (In BOURDIEU, P. Coisas Ditas. São Paulo: Brasiliense, 1990, p. 98), o que significa que o habitus é uma estrutura mas não é imutável, e sim está em constante reestruturação, pois as experiências acumulam saberes (In ACCARDO, Alain. "Initiation à la Sociologie" apud DESAULNIERS, J. B. R. A dinâmica estrutural do campo religioso: Alguns dados empíricos. Revista Veritas v 41, n. 162. Porto Alegre: EDIPUCRS, junho 1996c., p. 251).

" DESAULNIERS, Julieta. B. R. Formação, ou qualificaçäo, ou competência... Revista Veritas. Porto Alegre: EDIPUCRS, v. 38, n. 149, março/1993, p. 96.

7 DESAULNIERS, J. B. R. Formar o cidadão: um processo repleto de saberes. Trabalho apresentado no I Congresso Luso-Brasileiro de História da Educação "Leitura e Escrita" em Portugal e no Brasil - 1500/1970, Lisboa/Portugal, jan de 1996a. mimeo, p. 5.

- STROOBANTS, Marcelle. Travail et compétences: récapitulation critique des approches des savoirs au travail. In: Revue Formation/Emploi. Paris. Editions La Documentation Française, $n^{2} 33,1991, p$. 36 .

- LOPE, A y ARTLES, A.M. Las relaciones entre formación e empleo. Economia y Sociología del Trabajo. Madrid: Ministerio de Trabajo y Asuntos Sociales, n. 27/28, marzo-junio, 1995, p. 263 e 264. 
econômico, político e social, entre esses o desemprego e as novas formas de emprego, face à flexibilização do mercado de trabalho e à flexibilidade contratual no novo modo de gestão da mão-de-obra. ${ }^{10}$

O processo de formação, segundo a autora, engloba saberes que se referem não somente àqueles diretamente relacionados à tarefa especifica, pois passam a valer também os saberes sociais, informais, da experiência e tudo o que se constitui em acúmulo do trabalhador e que possa ser mobilizado no exercício do trabalho, garantindo-lhe, inclusive, maior versatilidade e flexibilidade no exercício de diferentes funções postas como necessidades na dinâmica do mercado. A formação é compreendida, assim, como um conjunto de ações que visam à orientação e integração do homem ao contexto social, ${ }^{11}$ envolvendo fatos referentes ao conjunto da vida, à totalidade das relações sociais.

No âmbito da formação, é a competência que vem sendo apontada como a categoria que sintetiza as alterações necessárias à construção do novo perfil de trabalhador requerido. Daí tomarmos essa categoria como a forma de formar de hoje e que pode ser desencadeada por uma diversidade de práticas sociais que, ao implicar inúmeros saberes, têm condições de instaurar a formação.

Daí pensarmos também que, sendo a demanda pelo perfil do trabalhador competente pautada em capacidades que requerem o desenvolvimento do espírito crítico, da participação, da criatividade e da autonomia, entre outras caracteristicas, há possibilidade de articulação entre formação voltada à competência e conseqüente ampliação e fortalecimento da cidadania, posto que a noção de competência supõe também que o indivíduo se capacite para a gestão de sua vida como um todo e não apenas no que se refere à atividade profissional que desempenha.

Sem dúvida, a competência é uma categoria considerada polêmica quanto às suas possibilidades e limites, pois gesta-se dentro da racionalidade instrumental e para atender aos requisitos da esfera econômica engendrada na dinâmica do capitalismo.

A busca dessa articulação entretanto é indicada pela necessidade de construção de um novo modelo emancipatório, conforme apontado por Demo, que viabilize o desenvolvimento de uma forma integrada, ou seja, onde o desenvolvimento econômico esteja a serviço da qualidade de vida, e onde a educação e o conhecimento sejam prioridade, pois a qualidade educativa da população é uma condição primordial para construirmos um projeto humanizado que consolide a cidadania. Trata-se não de colocar a cidadania à frente do mercado, pois não há como promover melhoria da qualidade de vida sem geração de excedente econômico, mas sim de articular ambas as instâncias. ${ }^{12}$

10 TANGUY, Lucie - Formação, uma atividade social em vias de definição? - apud COSTER e PICHAULT (organizadores) Traité de Sociologie du Travail. Bélgica. Ed. De Boeck - W, 1994.

" TANGUY, Lucie, apud DESAULNIERS, Julieta. A formação em busca da competência: Uma demanda da atualidade, $1996 \mathrm{~b}$. mímeo, p. 3

12 DEMO, Pedro. Cidadania Tutelada e Cidadania Assistida. Campinas, SP: Autores Associados, 1995, p. 4 e 5. Embora o autor utilize o termo educação, sua abordagem permite considerar que se refere ao que aqui denominamos formação, sentido mais abrangente e não restrito ao âmbito escolar/formal. 
Nesse sentido, algumas articulações podem ser visualizadas a partir das demandas do mundo do trabalho, pois os investimentos na formação do trabalhador, hoje bem expressa na categoria competência, de alguma forma podem possibilitar o avanço na ampliação e fortalecimento da cidadania. Por certo, as atividades de treinamento e desenvolvimento humano, a satisfação total do cliente, as melhorias no ambiente de trabalho, a participação, entre outros elementos que vêm sendo desenvolvidos pelos programas de qualidade e produtividade nas empresas, podem contribuir para o crescimento do trabalhador e para um ambiente de trabalho mais digno, gratificante e amadurecido, podendo significar, pelo menos, uma civilização do mercado.

Do que foi apontado até aqui, podemos considerar que as questões que estão presentes na contemporaneidade do mundo do trabalho, como a desproletarização do trabalho industrial, a subproletarização do trabalho e a. heterogeneização do trabalho, ${ }^{3}$ bem como a flexibilização das relações de trabalho e a exigência de um novo perfil do trabalhador, permitem uma diversidade de apreciações quanto às diferentes dimensões e tendências da chamada crise da sociedade do trabalho, bem como quanto às possibilidades ou não de transformar o trabalho alienado $\mathrm{e}$ explorado em um trabalho social que seja base para a emancipação do homem.

A análise do real exige, entre tantos possiveis matizes, olhar para a luz e para a sombra: se por um lado parece haver perspectiva de avanço em termos da autonomia e da participação do trabalhador, da qualificação, da competência e do desenvolvimento humano, decorrentes dos movimentos de qualidade e produtividade num mercado altamente competitivo, por outro há o aumento da exclusão, a precarização do trabalho, a perda ou fragilização dos direitos sociais conquistados e o recuo do movimento sindical, entre outros aspectos. A própria dinâmica dos interesses sociais em jogo coloca essas questões num campo de contradições e luta onde a formação voltada à competência e à cidadania se dá a partir das relações de força entre os agentes sociais, sendo também demandas dos trabalhadores no processo histórico de lutas e no movimento democrático.

A formação, seja do cidadão, seja do trabalhador competente, se dá permeada por relações de poder, dentro do contexto contraditório e multifacetado acima referido e é visualizada numa trajetória que apresenta descontinuidades que estão associadas às relações de disputa, conflitivas e/ou interativas, entre os agentes sociais no campo do poder (o político, o econômico e o social), basicamente a partir da dinâmica das relações Estado-sociedade civil, nos diferentes momentos históricos. O processo de formação se dá, então, nas relações de poder, através das instituições e das práticas sociais dos agentes, onde inserimos o SESI e as ações desencadeadas junto aos trabalhadores. Tal processo é permanentemente engendrado, nunca é algo dado, nem plenamente acabado.

\section{Formar para a competência: uma demanda atual}

A formação do trabalhador vem adquirindo importância cada vez mais reconhecida no contexto da educação e do trabalho, a partir das demandas pelo co-

13 ANTUNES, R. op. cit., p. 39 a 55. 
nhecimento e inovação constante. Conforme Frigotto, ${ }^{\text {th }}$ a explicitação do caráter orgânico das demandas por um trabalhador com uma nova "qualificação" no Brasil pode ser apreendida pelas próprias ações dos organismos da classe empresarial nacional, como CNI, FIESP, IEL, os quais vêm, crescentemente, dando importância à educação.

Essa necessidade de um novo perfil de trabalhador no sistema produtivo, como comentado, é conseqüência das modificações nos processos de trabalho e, conforme Lope y Artiles, das inovações a nível organizacional e técnico, parte delas com o objetivo de flexibilizar a produção e o uso da mão-de-obra, destacando-se o trabalho em equipes e a maior participação dos trabalhadores no planejamento, controle, manutenção e acompanhamento do processo produtivo.

Os referidos autores reforçam o que aqui tem sido colocado ao defenderem um conceito multidimensional de formação, que transcende aquela acadêmica e institucionalizada e define-se como um processo de "valoración social", o qual engloba não só conhecimentos técnicos, mas dimensões atitudinais e comportamentais inscritas no currículum oculto que é exigido para o acesso ao trabalho. Referem, ainda, que os requisitos básicos que as empresas têm feito a certos grupos de trabalhadores hoje são do tipo comportamental, onde parte das atitudes exigidas são contraditórias com as anteriormente vigentes e, por conseguinte, com os valores e normas de comportamento transmitidos pelo sistema educativo. Diante dessa realidade, identificam no conceito de formação aquelas dimensões mais eminentemente profissionais e aquelas ligadas ao processo de socialização e de configuração de atitudes e comportamentos, questionando até que ponto não são essas últimas que hoje tem maior incidência sobre o emprego ${ }^{15}$.

Dessa forma, as atuais demandas do mundo do trabalho não podem mais ser bem respondidas pelas noções de educação, preparação ou qualificação técnica, posto que requerem um trabalhador/cidadão com habilidades e capacidades mais abrangentes e complexas para operar com as novas tecnologias e estabelecer novas relações sociais e de trabalho, que se traduzem em mudanças no seu desempenho como trabalhador e cidadão.

Entretanto, freqüentemente encontramos na literatura pesquisada, principalmente na brasileira, o uso das noções de educação e qualificação, entre outras, para expressar o que aqui denominamos como formação, bem como o uso de noções como polivalência e multiqualificação, por exemplo, para expressar a competência. É o processo em gestação dessa nova realidade e das novas demandas que explica esse uso, de certa forma confuso, de uma diversidade de termos que, essencialmente, estão se referindo à mesma questão e buscam dar conta das mudanças em movimento no real, as quais exigem a construção de novas categorias capazes de apreender e expressar tais mudanças.

A diversidade de características apontadas como constituintes do novo perfil do profissional/trabalhador para os diferentes níveis hierárquicos das empresas,

14 FRIGOTTO, Gaudêncio. "Educação e formação humana: ajuste neoconservador e alternativa democrática". In GENTILI, Pablo A. A. e SLVA, T. T. da Neoliberalismo, Qualidade Total e Educação. Visões Críticas. 2 ed. RJ: Vozes, 1994, p. 38-39.

16

LOPE, A. y ARTLES, A.M. op. cit., p. 256, 260-265. 
bem como para autônomos ou terceirizados tem sido assinalada por diversas fontes, como, por exemplo, artigos e reportagens em revistas, periódicos e jornais, informativos específicos da área de recursos humanos, bem como nas reuniões de profissionais de diferentes áreas ligadas às organizações produtivas e em eventos científicos. Essa diversidade, por um lado, expressa que tais exigências não são as mesmas para todas as categorias de trabalhadores e postos de trabalho, como também expressa a complexidade e quantidade de capacidades e habilidades requeridas. Demonstra, ainda, a variedade de características que, aparecendo ou não diretamente articuladas à expressão competência, traduzem o que aqui estamos tomando como a totalidade das dimensões que entendemos que essa categoria vem condensando.

Sintetizando, as principais dimensões captadas no estudo dessas fontes ${ }^{16}$ são: criatividade; comunicação; capacidade para relacionar-se e para trabalho em equipe; maleabilidade intelectual, versatilidade; capacidade de antever e de resolver problemas; desenvolvimento de habilidades múltiplas, polivalência, multiqualificação; desenvolvimento de raciocínio lógico e pensamento abstrato-teórico; alfabetização computacional; constante mediação teoria-prática; capacidade de crítica e autonomia; responsabilidade e flexibilidade face à mudança; visão de empreendedor; iniciativa; motivação e capacidade para aprender; imaginação, ousadia, inovação; liderança; ética e honestidade; cooperação; atuação no âmbito da qualidade; aquisição e aplicação de conhecimentos transversais; visão transdisciplinar, conhecimento global e específico, inclusão de todos os saberes no processo; aprendizagem permanente; capacidade para articular os inúmeros saberes, inteligência ou quociente emocional (que implica autoconhecimento, administração das emoções, automotivação, empatia e relacionamento).

Numa matéria sobre o assunto, a Folha de São Paulo traz um artigo de Gifford Pinchot, ${ }^{17}$ consultor de empresas americano, o qual coloca que a empresa inteligente precisa utilizar a inteligência de todos os seus integrantes. Isso implica rever a organização hierárquica atual da empresas, posto que a mesma utiliza apenas a inteligência de uns poucos, limitando as interações e a cooperação. A empresa inteligente é, assim, aquela que utiliza o saber dos funcionários, troca informações livre e abertamente, permite liberdade de expressão e diálogo democrático, trabalha com sistemas auto-organizadores e inter-relacionados, tem o poder disseminado e não concentrado, dá condições de segurança e tem profunda preocupação ética.

Novos perfis de trabalhador vêm sendo necessariamente acompanhados, assim, de novos modelos de empresa, os quais apenas exemplificamos acima. É nesse contexto de mudanças que, dentro dos processos de formação do trabalhador, a categoria competência vem sendo utilizada enquanto categoria de análise que condensa elementos significativos do desenvolvimento capitalista nas últimas

${ }_{16}$ As caracteristicas citadas estão presentes em grande parte das obras citadas neste artigo, bem como em outras fontes consultadas, como artigos dos jormais Folha de São Paulo, Zero Hora, Correio do Povo e Fator RH, nos anos de 1995 e 1996.

17 PINCHOT, Grifford. "Organização Inteligente usa toda a capacidade de seus funcionários". Folha de São Paulo - encarte Folha Management n² 24. São Paulo, 22/01/96. 
décadas, em especial referentes às alterações que resultam em deslocamento de noções como a da qualificação à competệncia, na esfera do trabalho. ${ }^{18}$

A competência relaciona-se com a capacidade de mobilizar, junto aos postos de trabalho, conhecimentos/saberes adquiridos através da experiência social, 0 que implica formação. Essa noção baseia-se fundamentalmente nos resultados. ${ }^{19}$

A instauração da competência enquanto capacidade de resolver problemas em situações dadas é um processo inseparável da ação, ${ }^{\infty}$ cuja posse é medida em termos de "ser capaz de". ${ }^{21} \mathrm{E}$, ao implicar em uma articulação eficaz de diversos tipos de saberes junto aos postos de trabalho, o que requer a mobilização de várias capacidades da pessoa, a competência acena para o desenvolvimento do "ser" ou "saber- ser".

No atual estágio de desenvolvimento do capitalismo, é o capital humano que precisa ser desenvolvido em todas as suas dimensões, não numa perspectiva reducionista de formação de mão-de-obra. A tecnologia precisa de um indivíduo que conheça o processo como um todo, que pense de forma global e criativa e que saiba encontrar os problemas, as respectivas soluções ou saídas. Essa demanda requer o desenvolvimento humano em todas as dimensões, envolvendo capacidades e habilidades técnicas, sociais, emocionais, comportamentais e políticas, entre outras.

A competência supõe, assim, quantidade e diversidade de saberes e participação em vários processos de formação. Exige uma redefinição dos modelos pedagógicos em termos de métodos, processos, noções e mesmo das codificações e conceitos, posto que é baseada na capacidade de articular inúmeros saberes e não apenas de apreender aqueles diretamente ligados ao posto de trabalho ${ }^{2}$. A formação para a competência abrange uma diversidade de ações e práticas sociais, a nivel formal, informal e da experiência e, em síntese, capacita "o indivíduo a integrar os conhecimentos de maneira eficaz sobre objetos de ações". ".

O uso da noção de competência, na escola, empresa ou instituições de formação, segundo Tanguy, ${ }^{4}$ pode ser pensado em termos do sentido democrático moderno, pois, ao substituir uma representação da hierarquia de saberes e práticas por uma representação da diferenciação horizontal e não vertical, entre formas de saberes e formas de práticas, a noção de competências tende a dar importância às diferenças e particularidades individuais, mais do que à igualdade, possibilitando ao indivíduo, assim, singularizar-se com justiça. Esse enfoque permite pensar numa articulação entre cidadania e subjetividade na perspectiva da emancipação, podendo aproximar ainda mais claramente as categorias competência e cidadania.

18 DESAULNIERS, J. op. cit. p. 1 (1996b).

19 STROOBONTS, Marcelle. "Qualifications ou compétences? Des standards a geometril variable", citado In DESAULNIERS, J. B. R. op. cit., 1993, p. 101.

20 TANGUY, L. \& ROPÉ, F. Savoirs et Compétences. Paris: Hartmman, 1994, p. 14.

${ }^{21}$ Idem, p. 31 a 50.

a TANGUY, L. \& ROPE, F. op. cit., p. 31 a 50.

23 DESAULNIERS, J. B. R.. A dinâmica estrutural do campo religioso: Alguns dados empiricos. In: Veritas v 41, n. 162. Porto Alegre: EDIPUCRS, junho 1996c, p. 260. A autora apresenta esse conceito baseada em GILET, Pierre ( org). Construire la formation. Paris. Éditions E. S. P., 1991, p. 72.

TANGUY, L. \& ROPE, F. op. cit. p. 55. 


\section{Cidadania e competência, uma "nova" utopia?}

A articulação que vem sendo construída entre as categorias competência e cidadania está baseada tanto em um conceito de competência, quanto em uma concepção de cidadania.

Muito se tem falado e escrito sobre a cidadania. Seu exercício está presente no cotidiano, nas lutas, nas discussões, nas reflexões, nas reivindicações, nas reclamações, nos questionamentos, nas nossas práticas sociais diárias, assim como nos defrontamos cotidianamente com a sua manipulação e a sua negação. Entre tantas concepções e significados diferenciados, seu uso não deixa dúvidas quanto à importância que adquire na sociedade moderna, seja como instrumento do capital, seja como luta popular para efetiva realização e ampliação dos direitos do cidadão. Aliás, são nas próprias contradições do capital que vão se abrindo e ampliando os espaços para a sua construção.

Por outro lado, esse uso freqüente e até mesmo corriqueiro apresenta o risco de provocar uma vulgarização, um desgaste, uma banalização do termo e de seu potencial enquanto palavra de força para mobilizar ações e nortear projetos de desenvolvimento pautados em novos modelos econômico-sociais que estão em gestação. Entretanto, considerando a qualidade na vida, holisticamente compreendida, bem como a sustentabilidade humana, aspectos essenciais do desenvolvimento, a cidadania é, de fato, condição a ser continuamente criada, recriada, fortalecida e ampliada nas diferentes realidades e momentos sócio-históricos, guardando uma riqueza de possibilidades para o avanço de tais projetos.

Interessa-nos, aqui, enfocar a cidadania em termos de sua construção, o que, ainda assim, permite uma diversidade de olhares sobre as dimensões desse processo. Porém, voltando nosso foco à dimensão da formação do cidadão, destacamos aspectos relativos às demandas que se colocam em termos da aquisição e construção de capacidades, habilidades, atitudes...que podem contribuir para 0 processo de desenvolvimento intelectual, social, político e cultural do trabalhador, tendo em vista a construção e ampliação da cidadania, a partir do mundo do trabalho.

Spink, ao estudar a questão da cidadania do trabalhador na empresa, questiona as possibilidades ou não de avanços à cidadania dentro das atuais tendências do mundo do trabalho. Nesse sentido, identifica que o contexto das transformações na organização do trabalho, no interior das empresas, tem apontado para uma tendência ao discurso integrativo sobre os "recursos humanos", o qual faz parte de uma abordagem presente na administração de pessoal, identificada como "Human Resource Management" (HRM), onde uma forte cultura interna fornece o estímulo da equipe e o engajamento na missão da empresa. Não há, dentro da cultura que se cria na empresa, lugar nem razão para o trabalhador buscar apoio em estruturas extraorganizacionais, porque a própria empresa estaria sempre aberta às preocupações dos seus trabalhadores. ${ }^{2}$

2 SPINK, Peter. Cidadania na organização e cidadania da organização: notas para a desconstrução de "recursos humanos". In: SPINK, M. J. Paris (org.). A cidadania em Construção- uma reflexão transdisciplinar. São Paulo: Cortez, 1994, p. 111 a 114. 
O autor comenta que este é um estilo de relação empresa-funcionário que está sendo bastante divulgado no Brasil, pautado pelo discurso da "participação, motivação e qualidade" e denominado modelo do "cidadão da organização". Incorporando esse modelo, acredita que se corre o risco de negar os espaços que poderiam levar ao questionamento quanto ao papel do Estado na relação capitaltrabalho e na construção da cidadania. ${ }^{26}$

É importante considerar o ponto de vista do autor no contexto dessa investi-: gação, a fim de que possamos refletir criticamente sobre as efetivas possibilidades de articular as categorias competência e cidadania a partir da perspectiva desse estudo. Porém, exatamente na busca de construir um olhar sobre o real quej dê conta de suas múltiplas determinações e possibilidades é que esse ponto de vista necessita ser acrescido da consideração quanto ao espaço para a cidadania dentro das mudanças estruturais em curso no mundo do trabalho, o qual contém em si as contradições inerentes ao real, através das quais ocorrem tais processos de mudança.

A cidadania é concebida aqui a partir de um projeto de emancipação que, segundo Demo, requer a eliminação da pobreza política, enquanto núcleo principal da pobreza material. ${ }^{n}$ Ao abordar a questão da cidadania na perspectiva da emancipação, Demo enfoca a necessidade de articulá-la ao desenvolvimento da capacidade produtiva. A competência de fazer-se sujeito precisa ser correspondida com a competência da auto-sustentação, posto que não dá para vencer a pobreza política e permanecer dependente face à pobreza material ${ }^{2 s}$.

Dessa forma, ainda que considerando os movimentos apontados por Spink, parece-nos que o investimento nos trabalhadores demandados pelo mesmo modelo do cidadão na organização de que fala o autor pode facilitar o desenvolvimento de capacidades e habilidades e contribuir para a formação dos mesmos enquanto cidadãos plenos.

Para Demo, a formação da competência humana de fazer-se sujeito requer educação, organização política, identidade cultural, informação, comunicação e emancipação, a qual supõe capacidade crítica para intervir na realidade de uma forma alternativa e criativa. Trata-se, assim, de articular à formação da competência técnica-econômica (da qualidade formal, pelo conhecimento, necessária para civilizar o mercado), a competência política (pela educação). ${ }^{2}$

Embora o autor fale em competências e utilize o termo educação para expressar a competência política, o sentido de suas afirmações vem ao encontro do que estamos aqui colocando no que se refere à formação do cidadâo trabalhador. Contudo, a noção de competência abarca a totalidade das dimensões implicadas no processo de formação através de inúmeros saberes e prescinde, portanto, de classificações.

Da mesma forma, Demo fala na formação de um sujeito histórico competente, capaz de pensar e conduzir o seu destino, sobre o que colocamos um parênteses.

\footnotetext{
SPINK, P., op. cit., p. 115 e 117.

z DEMO, Pedro, op. cit. p. 30.

Idem, p. 136 e 137.

29 DEMO, Pedro, op. cit., p. 152 e 153.
} 
Adotamos aqui a perspectiva de Bourdieu, a partir da qual podemos falar de um indivíduo que é agente e não sujeito. Os agentes, na perspectiva do referido autor, atuam e sabem, tem capacidade para, são dotados de um senso prático, de um sistema adquirido de preferências e de princípios de visão e divisão (gosto), bem como de estruturas cognitivas duradouras (essencialmente pela incorporação das estruturas objetivas) e de esquemas de ação que orientam a percepção das situações e as respostas adequadas; não são, então, nem partículas mecânicas submetidas a forças mecânicas, nem sujeitos conscientes e conhecedores ${ }^{30}$ Para Bourdieu, as estruturas cognitivas não são formas de consciência, mas sim disposições corporais, crenças acerca do mundo social, profundamente enraizadas.

Entendemos, assim, que o espaço de liberdade e autonomia dos agentes existe numa articulação entre a estrutura estruturante e a estrutura estruturada e é possivel ser ampliado mediante rupturas que se estabelecem entre as estruturas mentais e estruturas objetivas. A superação da pobreza política de que fala Demo implica a realização de rupturas com toda uma relação histórica e culturalmente marcada pela dominação, a qual é baseada no poder simbólico, forma irreconhecível, transfigurada e legitimada das outras formas de poder e que, pelo trabalho de dissimulação e transfiguração, garante uma transubstanciação das relaçọ̃es de força, fazendo ignorar-reconhecer a violência que tais relações ençerram objetivamente. ${ }^{31}$ Romper com essa realidade requer revelar a verdade objetiva e aniquilar a crença, pela tomada de consciência do arbitrário. Apesar de serem produtos da estrutura, os agentes a criam e recriam constantemente, podendo até, sob certas condições, transformá-la mais ou menos radicalmente. Entretanto, essas rupturas não resultam apenas da: simples tomada de consciência: "a transformação das disposições não pode ocorrer sem uma transformação anterior ou concomitante das estruturas objetivas das quais elas são o produto e às quais podem sobreviver"."

É assim que o fortalecimento e ampliação da cidadania e a instauração da competênçia, que estão vinculados às mudanças em curso nos campos politico, econômico e social, têm a potencialidade de produzirem rupturas ou acrescentar novos elementos ao habitus dos trabalhadores e, nessa relação entre habitus e campos, podem produzir-se processos de mudança social.

A abordagem de Demo salienta também a questão da formação para a cidadania, que nos interessa especialmente, bem como aponta a necessidade de discussão e reformulação das próprias condições do mercado capitalista, o que é importante no contexto deste estudo, uma vez que é no movimento contraditório das novas demandas postas pelo mercado e pelos trabalhadores que vêm se reformulando a organização do trabalho e sendo requerido um novo perfil de trabalhador e de empresa, que supomos possa abrir novos espaços para o avanço da cidadania através da instauração da competência.

Na perspectiva de formação do cidadão há, ainda, toda uma cultura de submissão política que precisa ser superada, como aborda Sales, ao estudar as raizes

* BOURDIEU, Pierre. Razōes Práticas sobre a teoria da ação. Campinas, SP: Papirus, 1996, p. 41 e 42.

31 BOURDIEU, Pierre. O Poder Simbólico. Rio de Janeiro: Bertrand do Brasil S.A., 1989. p. 13-15.

32 BOURDIEU, P. op. cit., 1996, p. 117/118, 161 e 200. 


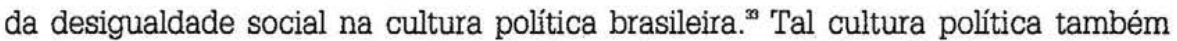
se faz presente nas relações de trabalho onde, associado às relações tayloristas, estiveram sempre presentes o clientelismo e o paternalismo. É preciso que, na perspectiva da formação do cidadão, se trabalhe no desenvolvimento da nossa cultura política que, historicamente, imprime-nos uma marca de submissão.

Visualizar a cidadania na perspectiva da cultura política e no contexto das diferentes formações sociais e econômicas e suas conjunturas implica olhar com mais atenção para a questão da cidadania no atual movimento neoliberal. Mais do que nunca, parece fundamental explicitar de que modelo de cidadania se fala, pois na ótica neoliberal a democracia tem apenas valor como um instrumento ou ferramenta que, entre outras, tem sua utilidade associada à possibilidade de viabilizar a liberdade econômica.

A noção de cidadania para nós contempla o direito a ter direitos e tem uma proposta de relações sociais mais igualitárias, a partir de novas formas de aprendizagem social e de convivência entre todos os cidadãos. Entre esses direitos incluise o próprio acesso a saberes e práticas sociais que permitam o desenvolvimento da subjetividade e a construção de outros tipos de convivência social e novas relações sociais. A formação do cidadão, além de considerar os determinantes históricos, econômicos, políticos e culturais dessa convivência, deve contemplar as dimensões estéticas, religiosas, morais, políticas e econômicas do cotidiano, articulando conteúdos e prática social, sensibilidade e razão. ${ }^{34}$

Tal visão bem demonstra a necessidade de, no processo de formação da competência e da cidadania, serem articulados inúmeros saberes, abarcando a totalidade das dimensões do indivíduo e das relações sociais.

As discussões acima permitem visualizar a possibilidade de articulação entre competência e cidadania, entretanto demonstram que tal articulação é complexa e coloca-se na dinâmica das relações de poder, conflitivas e/ou interativas, entre os agentes nos campos político, econômico e social. Esse processo se dá então num contexto de contradições e de luta e é permeado pelas relações de dispputa, onde os interesses dos diferentes grupos envolvidos, entre esses, políticos, empresários, trabalhadores e técnicos, bem como o volume global de capital que possuem e a estrutura de seu capital, ou seja, o peso relativo dos diferentes tipos de capital econômico e cultural no volume global de seu capital é que podem, em diferentes momentos, garantir ou não maior possibilidade de avanço nessa articulação.

Esse é o fundamento de diferenças nas disposições (habitus) dos agẹntes e, em decorrência, das suas tomadas de posição no espaço social. ${ }^{36}$ As estratégias dos agentes (e das instituições) envolvidos nas lutas, ou seja, suas tomadas de posição específicas, dependem da posição que ocupam na estrutura do campo, isto é, da distribuição do capital simbólico específico daquele campo e que, através da mediação das disposições constitutivas de seus habitus inclina-os a con-

3 SALES, Teresa. "Raizes da desigualdade social na cuitura política brasileira". Revista Brasileira de Ciências Sociais, ano 9, n. 25, jun/1994, p. 27, 31 e 34.

* FERREIRA, Nilda T. Cidadania, uma questão para a educação. Rio de Janeiro: Nova Fronteira, 1993 , p. 219 a 229.

3 BOURDIEU,P. op. cit., 1996, p. 18-21. 
servar ou a transformar a estrutura dessa distribuição. ${ }^{36}$ Daí a importância das alianças e estratégias empreendidas pelos agentes e da busca de associação de interesses a partir das demandas que estão se dando nos campos econômico e social.

É nesse contexto que pensamos o investimento na articulação dessas demandas, expressas na competência e na cidadania, como uma nova utopia.

\section{A formação do cidadão competente}

A crise da sociedade do trabalho está sendo discutida por autores que apontam variadas teses. Comentando brevemente 0 assunto, Frigotto ${ }^{x}$ exemplifica com as teses conservadoras do fim da história, de Fucuyama, a tese da sociedade do conhecimento, de Toffler, as teses de Kurz (1992), que postulam a autodissolução das classes e a "razão sensível" como novo ator social e, na mesma linha do fim da sociedade do trabalho e do conflito, o autor cita ainda Offe (1989) e Schaff (1990), que postulam questões como o sentido da vida e a preparação do homem para a sociedade do lazer.

No mesmo contexto dessas novas tendências, Drucker identifica que, atualmente, estamos atravessando uma transformação semelhante as que ocorrem na sociedade ocidental a cada dois ou três séculos, porém hoje esta transformação abrange o mundo como um todo e está criando a sociedade pós-capitalista, na qual alteram-se significativamente os fatores produtivos: 0 conhecimento e não 0 capital, passa a ser o fator decisivo na produção. As mudanças também ocorrem na sociedade em geral - onde destacam-se as organizações - e nas formas de governo, competindo e coexistindo diferentes estruturas transnacionais, de nações-estado, regionais e tribais A fase atual de desenvolvimento do capitalismo, segundo o autor, a da Revolução Gerencial, aponta a aplicação do conhecimento ao próprio conhecimento: é o conhecimento hoje que cria o valor no trabalho, seja pela produtividade ou pela inovação. ${ }^{*}$

É, com certeza, muito difícil defender uma posição inequívoca quanto a um possivel fim da sociedade do trabalho. Parece-nos possível afirmar, entretanto, que, dentro da complexidade e contraditoriedade que vem sendo assinalada, a centralidade da categoria trabalho na sociedade vem sendo verdadeiramente chacoalhada, o que indica, ao certo, que a concepção de trabalho, a forma como se trabalha, as relações de trabalho, a classe-que-trabalha vêm sofrendo sensiveis e profundas modificações, podendo mesmo vir a se constituir um novo conteúdo e forma para o trabalho na vida humana.

Nessa realidade vislumbrada, é fundamental ampliar as alternativas, equipar homem com uma rica e complexa gama de possibilidades e recursos que permitam a flexibilidade e versatilidade suficientes para lidar com a diversidade que está ai. Se a sociedade não mais se sustentará no trabalho, ou pelo menos na forma de se trabalhar até então conhecida, é preciso que se desenvolvam outras esferas

Idem, p. 63 e 64 .

37 FRIGOTTO, G. op. cit., p. 35.

DRUCKER, Peter. Sociedade Pós-Capitalista. Coleção Novos Umbrais. São Paulo: Pioneira, 1993, p. 1 a 25. 
sociais, que aprendamos ou valorizemos outras dimensões, habilidades, capacidades... que permitam formas criativas e novas de inserção na vida social e econômica. Dentro dessa perspectiva, é necessário avançarmos na formação do cidadão competente.

Não șe trata, assim, de negar o progresso técnico ou mesmo o potencial dos processos educativos de qualificação que estão se dando pelos movimentos de qualidade e produtividade. Trata-se, isso sim, como propõe Frigotto, de disputar o controle desses processos tornando-os efetivas possibilidades de avanço democrático, no sentido de reverter a dinâmica da exclusão em que permanecem inseridos, convertendo-os às necessidades da maioria.

A qualidade de vida e o desenvolvimento sustentável supõem investir na empregabilidade e nas possibilidades de acesso de todos aos bens e serviços da sociedade, dentro de critérios éticos, ampliando e fortalecendo a cidadania. Isso implica superar constantemente as contradições presentes no movimento, como por exemplo, a demanda por uma formação cada vez mais sólida, ao lado da crescente concentração do processo de produção de conhecimento, bem como a formação de trabalhadores polivalentes, flexiveis e criativos, mas submetida à lógica do mercado, ou seja, da exclusão e da segmentação.

Como chega a afirmar Antunes, a substituição do fordismo pelo toyotismo não deve ser entendida como um novo modo de produção societária, nem como um avanço em relação ao capitalismo da era fordista e taylorista. As singularidades da era toyotista, para o autor - maior participação do trabalhador na concepção do processo produtivo, por exemplo - não superaram o estranhamento, a alienação dada no/pelo trabalho. ${ }^{39}$ Apenas a lógica do toyotismo é mais consensual, envolvente, participativa e manipulatória, pois seu estranhamento é dado pelo envolvimento cooptado, através do qual o capital apropria-se do saber e do fazer do trabalho. ${ }^{\text {. }}$

A par das críticas apontadas e da contradição e complexidade próprias ao movimento do real, entendemos que dentro desse próprio quadro, que permite uma diversidade de leituras e possibilidades, é que vem sendo desenvolvidas, com relação à formação, novas propostas que acreditamos capazes de representar uma possibilidade de avanço para a classe trabalhadora e para a sociedade como um todo.

Dessa forma, embora as mudanças presentes no mundo do trabalho, bem condensadas nos correntes programas de Qualidade Total (TOC ou TOM), necessários ao desenvolvimento econômico brasileiro e a possibilidade e necessidade de uma posição no mercado internacional, empreendam como táticas de adesão o envolvimento e a questionável participação do trabalhador, entendemos que existe um efetivo espaço de avanço para a cidadania. À medida que se coloca como demanda um investimento significativo na formação do trabalhador, a partir da imprescindível valorização do capital humano, condição de sucesso de qualquer programa de qualidade, é que visualizamos tal perspectiva. A qualidade requerida no trabalho pressupõe qualidade de pessoas e qualidade de participação. Esse

39 Grifo do autor.

\$ ANTUNES, R. op. cit. p. 33 e 34. 
processo tem ocorrido de forma lenta, mas é crescente a constatação da necessidade desse investimento, o que vem acompanhado da modificação de elementos da cultura empresarial e organizacional, bem como da consciência da classe trabalhadora..

Por outro lado, a competência enquanto categoria em construção nos países chamados periféricos ou do Terceiro Mundo, onde se insere o Brasil, permite que se discuta neste momento histórico as próprias experiências já pesquisadas noutras realidades mais desenvolvidas, a fim de que possamos construir um modelo próprio de formação, que dê conta das necessidades do mercado (expressas na competência) articuladas às necessidades de desenvolvimento social e cultural (expressas na cidadania), dentro da nossa realidade e necessidades.

Como coloca Demo," se por um lado os sistemas produtivos modernos e competitivos reclamam um trabalhador educado numa ótica reducionista restrita à qualidade formal, excluindo a qualidade política, por outro, o próprio processo produtivo, ao exigir a inovação constante e requerendo educação permanente, inevitavelmente forma alguma dose de consciência crítica, podendo contribuir para a superação da pobreza política da população, condição para superação da pobreza material.

É dentro das perspectivas apontadas e no contexto mesmo das contradições que o SESI, que tem como clientela basicamente a classe trabalhadora da indústria e da construção civil, pode ter um importante espaço na dinâmica social, através do desenvolvimento de ações que contribuam para a formação requerida, numa perspectiva de gestão democrática e de ampliação da cidadania.

Pode a instituição contribuir efetivamente para desbloquear os mecanismos de exclusão e, da mesma forma, através dessas ações e partindo da realidade social, cultural, estética, valorativa, econômica e política dos trabalhadores participar da construção de um processo de relações democráticas voltadas à criação de condições que viabilizem um projeto de formação emancipatório? Tal participação, dentro da própria missão institucional, não se refere à formação técnica especializada, mas ao desenvolvimento daquelas capacidades e habilidades que vêm sendo apontadas como constituintes de um novo perfil do trabalhador, envolvendo mudanças de hábitos, atitudes e comportamentos, modificando mesmo as próprias relações sociais, numa perspectiva de qualidade de vida, cidadania e desenvolvimento sustentável, como a instituição se propõe.

Tendo por base essas considerações, o pressuposto central da investigação da qual esse artigo é parte é de que há uma descontinuidade no processo de formação desencadeado pela organização SESI, a partir das relações de disputa, conflitivas e/ou interativas, entre os agentes do campo econômico onde a mesma está inserida, e destes com os agentes dos campos político e social, dentro da dinâmica estrutural do campo do poder. A partir disto, supomos que:

- uma nova orientação no SESI, a nível nacional e regional, gestada a partir de 1989/90, caracterizada, basicamente, pela instauração do planejamento estratégico e participativo, desencadeia-se através de relações de disputa interna e externa,

41 DEMO, Pedro. op. cit., p. 5-36-65 e 66. 
num contexto de mudança que tende a fortalecer a instituição no espaço social enquanto um agente de formação da classe trabalhadora;

- a nova orientação, traduzida na missão, políticas, diretrizes e programas, favorece a formação na perspectiva da instauração da competência junto aos trabalhadores, o que se expressa pelos objetivos, conteúdos e metodologias das práticas institucionais pautadas na interdisciplinariedade, na interinstitucionalidade, na articulação teoria-prática, na multiplicidade de saberes e em relações democráticas. Esses elementos constituem-se em condições importantes para o desenvolvimento, junto ao trabalhador, de capacidades e habilidades requeridas na atualidade e condensadas na categoria competência.

- a formação na perspectiva da instauração da competência, ao constituir o saber-ser competente contribui para a instauração de um novo habitus junto aos trabalhadores, ampliando e fortalecendo a cidadania.

- o momento atual vivido pela organização, face às ameaças a sua sobrevivência advindas das relações de disputa na dinâmica estrutural do campo do poder, traz também oportunidades para a sua manutenção e ampliação no espaço social, porém requer o seu fortalecimento enquanto agente de formação no sentido da competência e da cidadania, com a atualização constante de suas respostas às demandas dadas no jogo de forças sociais. Nesse sentido, a construção de indicadores que traduzam as ações realizadas em termos da formação do cidadão trabalhador pode ser um importante elemento para o fortalecimento ou reformulação das práticas sociais desenvolvidas.

No atual estágio de desenvolvimento do capital, é o conhecimento que passa a desempenhar um papel decisivo tanto para a competitividade como para a cidadania. O conhecimento e a democratização são demandas também da classe trabalhadora. Nessa perspectiva, explicitar as possibilidades de instauração da competência e de construção da cidadania, a partir do mundo do trabalho e através da prática social empreendida pelo SESI, é uma tarefa que pode contribuir para o desenvolvimento social neste momento histórico.

\section{Referências Bibliográficas}

ANTUNES, Ricardo. Adeus ao Trabalho: Ensaio sobre as metamorfoses e a centralidade do Mundo do Trabalho - 2 ed. - São Paulo: Cortez, 1995.

BENEVIDES, Maria. V. de M. Cidadania e Democracia. In: Lua Nova - Revistade Cultura e Política São Paulo: CEDEC, n. 33, 1994.

BORDIEU, Pierre. O Poder Simbólico. Rio de Janeiro: Ed. Bertrand Brasil, 1989.

— Coisas Ditas. São Paulo: Brasiliense, 1990.

—. Razões Práticas - sobre a teoria da ação. Campinas, SP: Papirus, 1996.

DEMO, Pedro. Cidadania Tutelada e Cidadania Assistida - Campinas, SP: Autores Associados, 1995.

DESAULNIERS, Julieta B. R. Formação, ou qualificação, ou competência... In: Veritas - Porto Alegre: EDIPUCRS, v. 38, n. 149, março 1993.

- Formar o cidadāo: um processo repleto de saberes. Trabalho apresentado no $1^{2}$ CONGRES-

SO LUSO-BRASILEIRO DE HISTORLA DA EDUCAÇÄO - 1500/1970, em Lisboa/Portugal, de 23 a 26 de janeiro de 1996, mimeo, 1996a.

- Formaçāo em busca da competência: uma demanda da atualidade. mimeo, 1996b.

A dinâmica estrutural do campo religioso: Alguns dados empíricos. In: Veritas v. 41, n. 162.

Porto Alegre: EDIPUCRS, junho 1996c.

DRUCKER, Peter F. Sociedade Pós-Capitalista. São Paulo: Pioneira, 1993. 
ENGUITA, Mariano. Tecnologia e Sociedade: a ideologia da racionalidade técnica, a organização do trabalho e a educação. In: Revista Educação e Realidade - Porto Alegre: UFRGS, v. 1, n. 13, 1988.

FERREIRA, Nilda T. Cidadania, uma questāo para a educação. Rio de Janeiro: Nova Fronteira, 1993.

FRIGOTTO, Gaudêncio. Educação e formação humana: ajuste neoconservador e alternativa democrática. In GENTIII, Pablo A. A. e SILVA, T. T. da Neoliberalismo, Qualidade Total e Educaçăo. Visões Críticas. 2 ed. RJ: Vozes, 1994

GENTHI; Pablo A. A. \& SIVA, Tomaz Tadeu (orgs.). Neoliberalismo, Qualidade Total e Educação visões criticas. 2 ed. Petrópolis: Vozes, 1995.

IANNI, Otávio. A Sociedade Global. 3 ed. Rio de Janeiro: Civilização Brasileira, 1995.

LOPE, A y ARTLES, A.M. Las relaciones entre formación e empleo. Economía y Sociología del Trabajo. Madrid: Ministerio de Trabajo y Asuntos Sociales, n. 27/28, marzo-junio, 1995

ORTIZ, Renato (org.). Pierre Bordieu. Coleção Grandes Cientistas Sociais (39). São Paulo: Ática, 1983.

RÉGNIER, E. Martha. Desafios da Educação para o Terceiro Milênio: Breves Consideraçōes. Boletim Técnico do SENAC 19(1): 2-15, jan./abr. 1993.

SALES, Teresa. Raizes da desigualdade na cultura politica brasileira. Revista Brasileira de Ciências Sociais Estado/editora), ano 9, n. 25, jun. 1994.

SPINK, Peter. "Cidadania na organização e cidadania da organização: notas para a desconstrução de "recursos humanos". In: SPINK, M. J. Paris (org.). A cidadania em Construção - uma reflexâo transdisciplinar. São Paulo: Cortez, 1994.

STROOBANTS, Marcelle. Travail et compétences: récapitulation critique des approches des savoirs au travail. In: Revue Formation/Emploi. n. 33. Paris. Editions La Documentation Française, 1991.

TANGUY, Lucie - Formação, uma atividade social em vias de definição? - apud COSTER e PICHAULT (organizadores) Traité de Sociologie du Travail. Bélgica. Ed. De Boeck - W, 1994.

TANGUY, Lucie \& ROPÉ, Françoise. Savoirs et Competences. Paris: Ed. Hartmman, 1994. 